\title{
APPLYING METABOLIC FINGERPRINTING TO ECOLOGY: THE USE OF FOURIER-TRANSFORM INFRARED SPECTROSCOPY FOR THE RAPID SCREENING OF PLANT RESPONSES TO N DEPOSITION
}

\author{
ED GIDMAN ${ }^{1}$, ROYSTON GOODACRE $^{2}$, BRIDGET EMMETT $^{3}$, \\ LUCY J. SHEPPARD ${ }^{4}$, IAN D. LEITH ${ }^{4}$ and DYLAN GWYNN-JONES ${ }^{4, *}$ \\ ${ }^{1}$ Institute of Biological Sciences, University of Wales, Aberystwyth, Ceredigion, SY23 3DA, Wales, \\ UK; ${ }^{2}$ Department of Chemistry, UMIST, PO Box 88, Sackville Street, Manchester, M60 1QD, UK; \\ ${ }^{3}$ Centre for Ecology and Hydrology, Bangor, Deiniol Road, Bangor, LL57 2UW, UK; ${ }^{4}$ Centre for \\ Ecology and Hydrology, Edinburgh, Bush Estate, Penicuik, EH26 OQB, UK \\ (*author for correspondence, e-mail: dyj@aber.ac.uk, fax: +44 (0)1970 622350, \\ phone: 1970622318)
}

\begin{abstract}
The potential for metabolic fingerprinting via Fourier-transform infrared (FT-IR) spectroscopy to provide a novel approach for the detection of plant biochemical responses to $\mathrm{N}$ deposition is examined. An example of spectral analysis using shoot samples taken from an open top chamber (OTC) experiment simulating wet ammonium deposition is given. Sample preparation involved oven drying and homogenisation via mill grinding. Slurries of a consistent dilution were then prepared prior to FT-IR analysis. Spectra from control, 8 and $16 \mathrm{~kg} \mathrm{~N} \mathrm{ha}^{-1} \mathrm{yr}^{-1}$ treatments were then subjected to cross-validated discriminant function analysis. Ordination diagrams showed clear separation between the three $\mathrm{N}$ treatments examined. The potential for using Calluna vulgaris (L.) Hull as a bioindicator of $\mathrm{N}$ deposition is further evident from these results. The results also clearly demonstrate the power of FT-IR in discriminating between subtle phenotypic alterations in overall plant biochemistry as affected by ammonium pollution.
\end{abstract}

Keywords: ammonium deposition, Calluna vulgaris, chemometrics, critical load, metabolic fingerprinting, plant response

\section{Introduction}

Concern over deposition of atmospheric $\mathrm{NH}_{3}$ and $\mathrm{NH}_{4}^{+}$(collectively $\mathrm{NH}_{y}$ ) converting nutrient-poor ecosystems to those favouring nitrophilic plant species has been widely reported (Krupa, 2003). Particular interest has focused on Calluna vulgaris (L.) Hull because of its reported sensitivity to $\mathrm{NH}_{y}$ (Van Der Eerden et al., 1991; Pitcairn et al., 1995; Lee and Caporn, 1998; Carroll et al., 1999). Most published studies to date either concentrate on morphological responses (Carroll et al., 1999), alterations in physiology (Caporn et al., 1994) or simple aspects of shoot chemistry such as total N (Kirkham, 2001). Among other plant responses a positive correlation between shoot $\mathrm{N}$ and increasing $\mathrm{N}$ deposition has been observed (Pitcairn et al., 1995; Hicks et al., 2000). This relationship has led to foliar $\mathrm{N}$ concentrations in $C$. vulgaris being considered as a bio-indicator of $\mathrm{N}$ deposition and heath land

Water, Air, and Soil Pollution: Focus 4: 251-258, 2004.

(C) 2004 Kluwer Academic Publishers. Printed in the Netherlands. 
health (Pitcairn et al., 1995; Hicks et al., 2000). However, there is a suggestion that other factors influence foliar $\mathrm{N}$ in $C$. vulgaris (Hicks et al., 2000). Identification of a particular shoot chemistry response to $\mathrm{N}$ deposition, especially relating to exceedance of this species critical load, would therefore be extremely useful both to identifying early symptoms of critical load exceedance, and therefore damage, and in furthering its potential as a bioindicator. However, detection of responses around the critical loading of $10-15 \mathrm{~kg} \mathrm{~N} \mathrm{ha}^{-1} \mathrm{y}^{-1}$ (Ashmore et al., 2003) would require a more sensitive technique than those detailed above.

Metabolic fingerprinting allows rapid classification of a sample according to its origin or biochemical relevance (Fiehn, 2001; Johnson et al., 2003). The discipline has been described as obtaining "enough information to unravel (otherwise hidden) metabolic alterations without aiming to get quantitative data for all biochemical pathways" (Fiehn, 2001). Essentially this technique screens and produces a spectral description of a sample's entire biochemistry. Attempts can then be made to categorise samples based on potentially subtle alterations in their metabolic fingerprint. Hence, metabolic fingerprinting is considered 'hypothesis generating' (Kell and Oliver, 2004) because of its unbiased and holistic nature.

The techniques of nuclear magnetic resonance (NMR) (Lindon et al., 2000), Fourier-transform infrared spectroscopy (FT-IR) (Timmins et al., 1998; Gidman et al., 2003; Johnson et al., 2003), electrospray ionisation mass spectrometry (ESI-MS) (Vaidyanathan et al., 2001, 2002; Goodacre et al., 2002) and Fouriertransform ion cyclotron mass spectrometry (FT-MS) (Aharoni et al., 2002) are all examples of rapid analytical methods that are capable of performing this form of analysis. The highly complex 'fingerprints' obtained by these methods (see Figure 1 for example) are interpreted using chemometric methods (Massart et al., 1988; Martens and Næs, 1989) including principal components analysis (PCA) (Jolliffe, 1986) and discriminant function analysis (DFA) (Manly, 1994; Timmins et al., 1998). The particular metabolic fingerprinting method that we have examined and subsequently report on within this paper is FT-IR.

FT-IR is a high-throughput and relatively inexpensive metabolic fingerprinting technique that measures molecular functional group vibrations (Goodacre et al., 1998; Timmins et al., 1998; Ellis et al., 2003). In this capacity, as opposed to conventional techniques like total $\mathrm{N}$ assays, measurements are not constricted to particular regions of chemistry or compounds. Instead FT-IR essentially allows a 'snap-shot' of a sample's entire chemistry at a given point in time to be taken. FT-IR has already been proved to be a successful technique in the differentiation of bacterial and fungal species (Helm et al., 1991; Goodacre et al., 1998; Timmins et al., 1998), detection of meat spoilage (Ellis et al., 2002), examination of salinity effects on tomato fruit (Johnson et al., 2003), investigation of intracellular macromolecular pools in marine microalgae (Giordano et al., 2001) and the investigation of plant-plant interference (Gidman et al., 2003). Here we investigate whether FT-IR can detect changes in $C$. vulgaris biochemistry induced by $\mathrm{NH}_{4}^{+}$increases over a deposition range that crosses the critical load for $C$. vulgaris heathlands. 


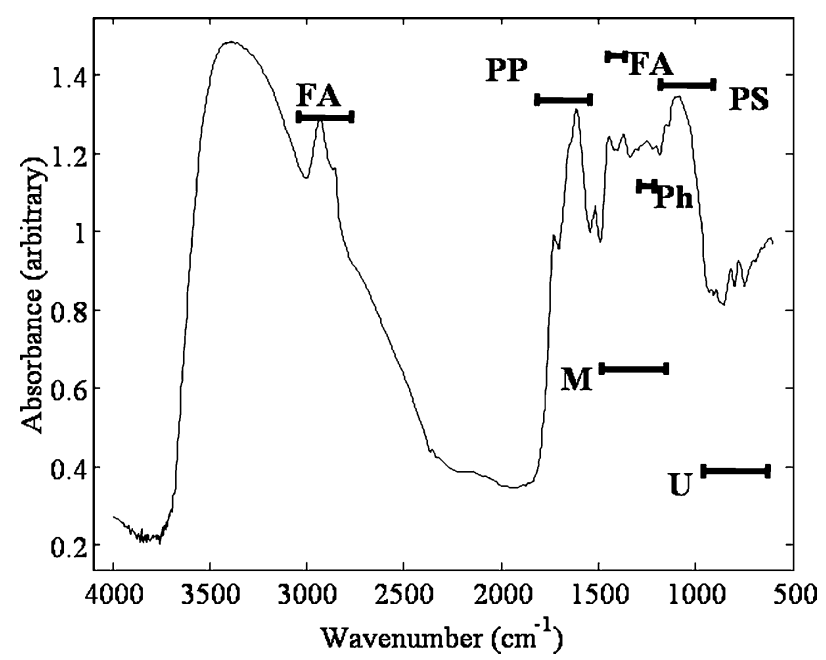

Figure 1. Typical raw FT-IR spectra of C. vulgaris oven-dried shoot tissue. Regions that experience functional group vibrations that relate to particular molecular species are highlighted; $\mathrm{FA}=$ fatty acids, $\mathrm{PH}=$ phosphates, $\mathrm{PP}=$ peptides, $\mathrm{PS}=$ polysaccharides, $\mathrm{U}=$ unassigned and $\mathrm{M}=$ mixed region of proteins, fatty acids, phosphate rich.

\section{Materials and Methods}

\subsection{EXPERIMENTAL DESIGN AND SAMPLE ACQUISITION}

C. vulgaris samples were collected from the Centre for Ecology and Hydrology's (CEH) OTC site (18 km SW of Edinburgh). During the summer of 1998, a central square in each OTC was excavated to $3 \mathrm{~m}^{2}$ by $0.5 \mathrm{~m}$ deep. This excavation was then back-filled with peat and individual young $(<3 \mathrm{y})$ plants of seven species, taken from a nearby ombrotrophic bog (Leith et al., 2001, 2002). Overall six $\mathrm{NH}_{4}^{+}-\mathrm{N}$ deposition treatments, applied as $\mathrm{NH}_{4} \mathrm{Cl}$ mist, and five gaseous $\mathrm{NH}_{3}$ deposition treatments exist. However, for the purpose of this paper, only three of the misting treatments are discussed (de-ionised water control, 8 and $16 \mathrm{~kg} \mathrm{~N} \mathrm{ha}^{-1} \mathrm{y}^{-1}$ ). A full description of the experimental design can be found in Leith et al. (2001) and a description of the OTCs can be found in Fowler et al. (1989).

C. vulgaris samples were taken during October 2002. Four shoots, each about $4 \mathrm{~cm}$ in length, of current years growth were selected per plant and these samples were transported on ice. Samples were then oven-dried at $80{ }^{\circ} \mathrm{C}$ for $48 \mathrm{~h}$ before being sent to University of Wales, Aberystwyth (UWA) for FT-IR analysis.

\subsection{FOURIER-TRANSFORM INFRARED SPECTROSCOPY}

Samples were oven-dried upon arrival at UWA at $60-80{ }^{\circ} \mathrm{C}$ for a period of $48 \mathrm{~h}$ and then allowed to cool inside desiccators. Sample homogenisation was 
then performed by ball milling at $30 \mathrm{~Hz}$ for $30 \mathrm{~s}$. $\sim 20 \mathrm{mg}$ of powder per sample was placed in $2 \mathrm{ml}$ Eppendorf tubes before addition to the FT-IR plate. Immediately prior to analysis, samples were diluted with MilliQ $\mathrm{H}_{2} \mathrm{O}$ to a constant factor of 100 $\mathrm{mg} \mathrm{ml}^{-1}$, the resultant slurries were applied to a 100 well aluminium plate and oven-dried for $30 \mathrm{~min}$ at $50^{\circ} \mathrm{C}$. The FT-IR instrument used was a Bruker IFS28 FTIR spectrometer (Bruker Spectrospin Ltd., Banner Lane, Coventry, UK) equipped with a mercury-cadmium-telluride detector (more detail on the FT-IR equipment can be found in Timmins et al., 1998). Each sample, once analyzed, was represented by a spectrum containing 882 points ( Figure 1) and spectra were displayed in terms of absorbance as calculated from the reflectance-absorbance spectra using the Opus software (which is based on the Kubelka-Munk theory (Griffiths and de Haseth, 1986)).

\subsection{SPECTRAL PROCESSING AND CHEMOMETRIC ANALYSIS}

Spectra were processed prior to analysis in order to minimise spectral baseline shifts (Timmins et al., 1998; Gidman et al., 2003). This involved replacing $\mathrm{CO}_{2}$ peaks (wavenumbers $2403-2272 \mathrm{~cm}^{-1}$ and $683-656 \mathrm{~cm}^{-1}$ ) with a smooth trend, normalising the spectra so that the minimum and maximum absorbancies were set to 0 and +1 respectively, and finally detrending the minimum and maximum wavenumbers of the spectra to 0 (Timmins et al., 1998; Gidman et al., 2003). Initially, cluster analysis involved the reduction of the multidimensional FT-IR data by PCA (Jolliffe, 1986) according to the NIPALS algorithm (Wold, 1966). DFA, also known as canonical variates analysis (CVA), then discriminated between spectra using the retained principal components and the a priori knowledge of spectral treatment grouping. In order to assess whether the analysis was biased due to the high level of a priori knowledge an independent test set, taken prior to analysis from the data set in question, was generated randomly and projected into the DFA space (Radovic et al., 2001). Succesful validation, arising from test set spectra projecting into their relavant clusters, confirms real separation. Thus, DFA analysis was repeated on the entire data set, comprising both training and test sets whereas otherwise no differences between groups would have been assumed. These cluster analysis methods were implemented using Matlab version 5 (The Math Works, Inc., 24 Prime Par Way, Natick, MA, U.S.A.), which runs under Microsoft Windows NT on an IBM-compatible PC.

\section{Results}

The analysis by DFA, shown in Figure 2, provided good clustering between all three treatments (control, 8 and $16 \mathrm{~kg} \mathrm{~N} \mathrm{ha}^{-1} \mathrm{y}^{-1}$ ). Two effects appear discernible from the DFA plot. Examination of the first discriminant function (DF) shows apparent separation between the control and $\mathrm{N}$ treated spectra. The second DF appears to 


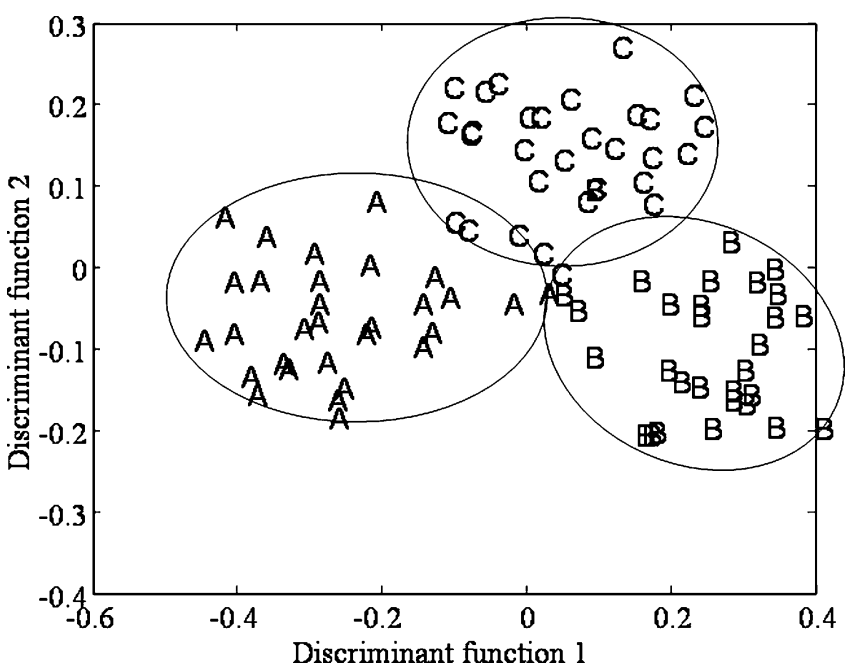

Figure 2. DFA ordination plot of $C$. vulgaris spectra using 17 principal components (explaining $99.74 \%$ of the total variance). Separation shown for plants subjected to 0 (A), 8 (B) and 16 (C) $\mathrm{kg}$ $\mathrm{NH}_{4} \mathrm{ha}^{-1} \mathrm{yr}^{-1}$. DFA a priori class structure based on grouping all spectra per treatment (one $a$ priori class per treatment). Previous cross-validation ( $n=7$ for training, $n=3$ for testing) validated this analysis (results not shown).

describe increases in $\mathrm{N}$ addition, from 8 to $16 \mathrm{~kg} \mathrm{~N} \mathrm{ha}^{-1} \mathrm{y}^{-1}$, although here the control spectra cluster overlaps with both of the two $\mathrm{N}$ treatment clusters. Considering both DFs share a similar scale (from about -0.4 to +0.4 ) both contain equally important effects in terms of the model. Previous cross-validation of this model confirmed that the observed separation is not simply an artefact of the analytical procedure.

\section{Discussion}

Our results clearly show that wet application of $\mathrm{NH}_{4} \mathrm{Cl}$ alters $C$. vulgaris shoot chemistry. Additionally, the FT-IR method can discriminate between effects caused by simulated depositions of 8 and $16 \mathrm{~kg} \mathrm{~N} \mathrm{ha}^{-1} \mathrm{y}^{-1}$. This is important as this relatively small range crosses the critical load for $\mathrm{N}$ for UK upland Calluna heaths (Ashmore et al., 2003). This strongly suggests that metabolic fingerprinting can detect shoot biochemistry fluctuations arising from $\mathrm{NH}_{4}^{+}$deposition in the field and may be useful in identifying pre-symptomatic changes. Furthermore, considering the technique used oven-dried whole shoot tissue, no initial assumption concerning shoot biochemistry fluctuations was required. This underlines the techniques 'hypothesis generating' power, and thus allows further exploration through more advanced metabolomic methods and chemometrics to target specific metabolites. 
Further analysis of the data using more powerful machine learning methods such as artificial neural networks (Warner and Misra, 1996; Goodacre et al., 1998) and genetic algorithms (Davies et al., 2000; Johnson et al., 2003) may be able to narrow the difference seen down to a particular region of the metabolome. This knowledge would allow targeted metabolite analyses to elucidate the particular changes in metabolic chemistry due to $\mathrm{NH}_{y}$ treatment.

FT-IR has lower resolution compared with other fingerprinting methods such as NMR, GC-MS or ESI-MS, meaning its ability to identify specific metabolites is relatively poor. This could hamper the sensitivity of the technique when compounds at trace levels are involved in plant responses, especially considering the complexity of the resultant data obtained from whole oven-dried plant tissue. Chemometric data mining techniques are therefore still under development, and here the aim is to determine how much useful information can be derived from FT-IR spectra. However, it does have the benefit of being high-throughput.

A trade-off between ability to successfully identify metabolites and speed exists. Hence, analysis times of about $10 \mathrm{~s}$ per sample are typical of FT-IR, whereas with NMR and MS techniques a single sample takes several minutes to analyse. Not only does FT-IR have relative rapidity, it is also cost effective and not biased to any chemical species unlike NMR and MS. Additionally, as shown here, the results from the OTC experiment clearly illustrate the technique's potential for the future as a primary screening method before targeted analysis.

Overall, FT-IR has been shown to be a powerful tool in the high-throughput screening of plant tissue. Further development may prove that FT-IR is a valuable addition in understanding plant biochemistry responses to environmental factors, especially alongside conventional chemical analyses and more powerful metabolomic techniques, such as MS (Fiehn, 2001). Current work is assessing the techniques potential to determine $\mathrm{NH}_{y}$ response detection using $C$. vulgaris plant tissue obtained from the field, and to determine if the $\mathrm{N}$ signal is masked by other sources of variability such as climate, age, grazing pressure and $\mathrm{N}$ form.

\section{Acknowledgements}

The authors are grateful to the NERC for funding a CASE PhD under the GANE consortium for Ed Gidman. The staff of CEH Bush are thanked for their assistance in sample collection from their OTC experiment and the UK Department of the Environment, Transport and the Regions (Contract no. EPG 1/3/94) and NERC are thanked for their financial support towards this project. David I. Ellis is thanked for his technical assistance with FT-IR operation. Finally, we would like to show our continued appreciation to Dr. Helen Johnson for her assistance in chemometric analysis and current maintenance of the FT-IR apparatus. 


\section{References}

Aharoni, A., Ric de Vos, C. H., Verhoeven, H. A., Maliepaard, C. A., Kruppa, G., Bino, R. and Goodenowe, D. B.: 2002, 'Nontargeted metabolome analysis by use of Fourier transform ion cyclotron mass spectrometry', Omics 3, 217-234.

Ashmore, M., Reynolds, B. and Hornung, M.: 2003, 'Development of empirical critical loads', in B. A. Emmett and B. L. Williams (eds.), NERC-DEFRA Terrestrial Umbrella Annual Report, August 2003, pp. 3-6.

Caporn, S. J. M., Risager, M. and Lee, J. A.: 1994, 'Effect of nitrogen supply on frost hardiness in Calluna vulagris (L.) Hull', New Phytol. 128, 461-468.

Carroll, J. A., Caporn, S. J. M., Cawley, L., Read, D. J. and Lee, J. A.: 1999, 'The effect of increased deposition of atmospheric nitrogen on Calluna vulgaris in upland Britain', New Phytol. 141, 423-431.

Davies, Z. S., Gilbert, R. J., Merry, R. J., Kell, D. B., Theodorou, M. K. and Griffith, G. W.: 2000, 'Efficient improvement of silage additives by using genetic algorithms', Appl. Environ. Microb. 66, 1435-1443.

Ellis, D. I., Harrigan, G. G. and Goodacre, R.: 2003, 'Metabolic fingerprinting with Fourier-transform infrared spectroscopy', in G. G. Harrigan and R. Goodacre (eds.), Metabolic Profiling: Its Role in Biomarker Discovery and Gene Function Analysis, Kluwer Academic Publishers, Dordrecht, The Netherlands, pp. 111-124.

Ellis, D. I., Broadhurst, D., Kell, D. B., Rowland, J. J. and Goodacre, R.: 2002, 'Rapid and quantitative detection of the microbial spoilage of meat by Fourier-transform infrared spectroscopy and machine learning', Appl. Environ. Microb. 68, 2822-2828.

Fiehn, O.: 2001, 'Combining genomics, metabolome analysis, and biochemical modelling to understand metabolic network', Comp. Funct. Genom. 2, 155-168.

Fowler, D., Cape, J. N., Deans, J. D., Leith, I. D., Murray, M. B., Smith, R. I., Sheppard, L. J. and Unsworth, M. H.: 1989, 'Effects of acid mist on the frost hardiness of red spruce seedlings', New Phytol. 113, 321-335.

Gidman, E., Goodacre, R., Emmett, B., Smith, A. R. and Gwynn-Jones, D.: 2003, 'Investigating plant-plant interference by metabolic fingerprinting', Phytochem. 63, 705-710.

Giordano, M., Kansiz, M., Heraud, P., Beardall, J., Wood, B. and McNaughton, D.: 2001, 'Fouriertransform infrared spectroscopy as a novel tool to investigate changes in intracellular macromolecular pools in the marine microalga Chaetoceros muellerii (Bacillariophyceae)', J. Phycol. 37, 271-279.

Goodacre, R., Vaidyanathan, S., Bianchi, G. and Kell, D. B.: 2002, 'Metabolic profiling using direct infusion electrospray ionisation mass spectrometry for the characterisation of olive oils', Analyst 11, 1457-1462.

Goodacre, R., Timmins, E. M., Burton, R., Kaderbhai, N., Woodward, A. M., Kell, D. B. and Rooney, P. J.: 1998, 'Rapid identification of urinary tract infection bacteria using hyperspectral wholeorganism fingerprinting and artificial neural networks', Microbiol. 144, 1157-1170.

Griffiths, P. R. and de Haseth, J. A.: 1986, Fourier Transformed Infrared Spectrometry, John Wiley, New York.

Helm, D., Labischinski, H., Schallehn, G. and Naumann, D.: 1991, 'Classification and identification of bacteria by Fourier-transform infrared spectroscopy', J. Gen. Microbiol. 137, 69-79.

Hicks, W. K., Leith, I. D., Woodin, S. J. and Fowler, D.: 2000, 'Can the foliar nitrogen concentration of upland vegetation be used for predicting atmospheric nitrogen deposition? Evidence from field surveys', Environ. Pollut. 107, 367-376.

Johnson, H. E., Broadhurst, D., Goodacre, R. and Smith, A. R.: 2003, 'Metabolic fingerprinting of salt-stressed tomatoes', Phytochem. 62, 919-928.

Jolliffe, I. T.: 1986, Principal Component Analysis, Springer-Verlag, New York. 
Kell, D. B. and Oliver, S. G.: 2004, 'Here is the evidence, now what is the hypothesis? The complementary roles of inductive and hypothesis-driven science in the post-genomic era', Bioessays 26, 99-105.

Kirkham, F. W.: 2001, 'Nitrogen uptake and nutrient limitation in six hill moorland species in relation to atmospheric nitrogen deposition in England and Wales', J. Ecol. 89, 1041-1053.

Krupa, S. V.: 2003, 'Effects of atmospheric ammonia $\left(\mathrm{NH}_{3}\right)$ on terrestrial vegetation: A review', Environ. Pollut. 124, 179-221.

Lee, J. A. and Caporn, S. J. M.: 1998, 'Ecological effects of atmospheric reactive nitrogen deposition on semi-natural terrestrial ecosystems', New Phytol. 139, 127-134.

Leith, I. D., Pitcairn, C. E. R., Sheppard, L. J., Hill, P. W., Cape, J. N., Fowler, D., Tand, S., Smith, R. I. and Parrington, J. A.: 2002, 'A comparison of impacts of $\mathrm{N}$ deposition applied as $\mathrm{NH}_{3}$ or as $\mathrm{NH}_{4} \mathrm{Cl}$ on ombrotrophic mire vegetation', Phyton (Horn, Austria) 42, 83-88.

Leith, I. D., Sheppard, L. J., Pitacairn, C. E. R., Cape, J. N., Hill, P. W., Kennedy, V. H., Tang, Y. S., Smith, R. I. and Fowler, D.: 2001, 'Comparison of the effects of wet $\mathrm{N}$ deposition $\left(\mathrm{NH}_{4} \mathrm{Cl}\right)$ and dry $\mathrm{N}$ deposition $\left(\mathrm{NH}_{3}\right)$ on UK moorland species', Water Air Soil Pollut. 130, 1043-1048.

Lindon, J. C., Nicholson, J. K., Holmes, E., Everett, J. R.: 2000, 'Metabonomics: Metabolic processes studied by NMR spectroscopy of biofluids', Concept. Magnetic Res. 12, 289-320.

Manly, B. F. J. (ed.): 1994, Multivariate Statistical Methods: A Primer, Chapman \& Hall, London.

Martens, H. and Næs, T.: 1989, Multivariate Calibration, John Wiley and Sons, New York.

Massart, D. L., Vandeginste, B. G. M., Deming, S. N., Michotte, Y. and Kaufmann, L.: 1988, Chemometrics: A Textbook, Elsevier, Amsterdam.

Pitcairn, C. E. R., Fowler, D. and Grace, J.: 1995, 'Deposition of fixed atmospheric nitrogen and foliar nitrogen content of bryophytes and Calluna vulgaris (L.) Hull', Environ. Pollut. 88, 193-205.

Radovic, B. S., Goodacre, R. and Anklam, E.: 2001, 'Contribution of pyrolisis mass spectrometry (Py-MS) to authenticity testing of honey', J. Anal. Appl. Pyrol. 60, 79-87.

Timmins, E. M., Howell, S. A., Alsberg, B. K., Noble, W. C. and Goodacre, R.: 1998, 'Rapid differentiation of closely related Candida species and strains by pyrolysis-mass spectroscopy and Fourier-transform infrared spectroscopy', J. Clin. Microbiol. 36, 367-374.

Vaidyanathan, S., Kell, D. B. and Goodacre, R.: 2002, 'Flow-injection electrospray ionization mass spectrometry of crude cell extracts for high-throughput bacterial identification', J. Am. Soc. Mass Spectr. 13, 118-128.

Vaidyanathan, S., Rowland, J. J., Kell, D. B. and Goodacre, R.: 2001, 'Discrimination of aerobic endospore-forming bacteria via electrospray-ionization mass spectrometry of whole cell suspensions', Anal. Chem. 73, 4134-4144.

Van Der Eerden, L. J., Dueck, T. H. A., Berdowski, J. M. M., Greven, H. and Van Dobben, H. F.: 1991, 'Influence of $\mathrm{NH}_{3}$ and $\left(\mathrm{NH}_{4}\right)_{2} \mathrm{SO}_{4}$ on heathland vegetation', Acta Bot. Neerl. 40, 281-296.

Warner, B. and Misra, M.: 1996, 'Understanding neural networks as statistical tools', Am. Stat. 50, 284-293.

Wold, H.: 1966, 'Estimation of principal components and related models by iterative least squares', in K. R. Krishnaiah (ed.), Multivariate Analysis, Academic Press, New York, pp. 391-420. 